\title{
Р.Ж. Тулеушова
}

Каспийский Университет, Алматы, Республика Казахстан

\author{
R.Zh. Tuleushova
}

Caspian University, Almaty, Republic of Kazakhstan ratu@inbox.ru

\section{ЗАДАЧИ И ПРИНЦИПЫ АКТИВНОГО ДЕМПФИРОВАНИЯ КОЛЕБАНИЙ БАЛОЧНОГО ПРОЛЕТА МОСТА}

\section{TASKS AND PRINCIPLES OF ACTIVE DAMPING OF VIBRATION FLIGHTS}

Бул эмгекте көпүрөнүн конструкииясына сейсмикальк таасирге каршы таасирдин модели каралган. Ал модель активдүу демпфирлөөчу курулумадан турат. Сунушталган ынманын мааниси - активдүҮ демпфир аральк курулма катары жардамчы ролду ойнойт жана натыйжалуу демпфирлөөнүн зарыл болгон гистерезистүҮ мунөздөмөсүн аныктоого өбөлгө болот. Аныкталган оптималдуу гистерезистүҮ мүнөздөмөлөр боюнча корголуучу обьектиге орнотулуучу пассивдүу демпфердин параметрлерин аныктоого мумкүнчүлүк болот. Активдүу демпфер атайыл сыноочу стендде орнотулушу же виртуалдык сандык экспериментте колдонулушу мумкүн. Сандык моделдөө Үчүн активдүҮ демпфирлөөнүн математикальк модели иштелип чыккан, анда сейсмикальк таасирдин импульстук мүнөзу эске алынган жана салттык гармоникалык анализге тиешелҮY чектөөлөрдү кеңейтет.

өзөк сөздөр: активдүY демпфирлөө, сейсмикальк таасир, өткөөл бөлүктүн термелҮүсү, мейкиндикте чубалган обьектинин мониторинги.

В работе рассматриваются модель противодействия сейсмическому воздействию на мостовую конструкиию, создаваемого активным демпфирующчи устройством. Суть предложенного подхода в том, что активный демпфер играет вспомогательную роль в качестве промежуточного устройства, позволяющего определить необходимье гистерезисные характеристики эффективного демпфирования. По выявленным оптимальным гистерезисным характеристикам можно определить параметры пассивных демпферов, предназначенных для непосредственной установки на защищаемом объекте. Активный демпфер может быть реализован как устройство на специализированом испьтательном стенде, либо виртуально в численных экспериментах. Для численного моделирования была разработана математическая модель активного демпфирования, учитывающая импульсный характер сейсмических воздействий и тем самым расширяющая ограничения присущие традиционному гармоническому анализу.В этой модели предложень сверточные представления динамических величин, эквивалентные введению слабой меры динамических функичий в пространстве мостовых колебаний. Этот подход в большей степени отвечает задачам инженерных приложений.

Ключевые слова: активное демпфирование, сейсмическое воздействие, колебания пролетной части, мониторинг пространственно протяженных объектов.

The paper considers a model for counteracting seismic effects on a bridge structure created by an active damping device. The essence of the proposed approach is that the active damper plays an auxiliary role as an intermediate device that allows you to determine the necessary hysteresis characteristics of effective damping. Based on the identified optimal hysteresis characteristics, it is possible to determine the parameters of passive dampers intended for direct installation on the protected object. 
An active damper can be implemented as a device on a specialized test bench, or virtually in numerical experiments. For numerical modeling, a mathematical model of active damping was developed, taking into account the pulsed nature of seismic effects and thereby expanding the limitations inherent in traditional harmonic analysis. In this model, convolutional representations of dynamic quantities are proposed, equivalent to the introduction of a weak measure of dynamic functions in the space of bridge oscillations. This approach is more responsive to the challenges of engineering applications.

Key words: active damping, seismic action, fluctuations of the bridge constructions, monitoring, extended object tracking.

Введение. Демпферы колебаний мостовых конструкций изначально предназначены дляамортизации аномальных нагрузок. Ктакимможно отнестисредние и сильные сейсмические возмущения, нерасчетные нагрузки от трафика, а также опасныеклиматические воздействия.

Вместе с тем, даже при нормальном режиме работы конструкции сооружения демпфирующие устройства могут влиять на спектр колебаний конструкции и, тем самым участвовать в управлении надежностью сооружения. Управление надежностью мостовой конструкции путем воздействия на спектр нормальных колебаний, в частности основано на существовании гармоник, резонирующих с отдельными элементами конструкции даже при некритичном в целом характере колебаний. Примером может служить ослабление натяжения болтов, подвергшихся коррозии на Эресуннском мосту (Дания-Швеция, 2001г.)[1]. Этот пример показывает, что в процессе эксплуатации сооружения может появиться необходимость в подавлении нежелательных тонов в режиме колебаний с нормальной амплитудой.

Для управляемого демпфирования мост необходимо оснастить системой мониторинга, передающей в реальном времени данные о динамическом состоянии пролетной части: профиль прогиба по длине пролета, а также значения мгновенных скоростей и ускорений, распределенных по профилю пролета.

Пролет моста и активный демпфер образуют механический колебательный контур. В управляемом случае параметры контура можноизменятьсоответственносигналам системы мониторинга, следовательно, данный контур работает под управлением обратной связи.

Описать процесс воздействия на спектр колебаний пролетной части можно рассмотревобобщенноеактивноеустройстварегулирования (рис.1), т.е. активный демпфер, который использует данные системы мониторинга о статическом и динамическом состоянии всейпролетной части для выработки закона управления исполнительным механизмом.

Исполнительный механизм имеет привод для создания реактивного (противодействующего внешней нагрузке) усилия, передаваемого мостовой балке. Закон изменения реактивной силы в зависимости от мгновенного прогиба балки в точке соединения демпфера с пролетом является главной характеристикой демпфирующего устройства. Пусть $\eta$-смещение демпфера от положения равновесия. Тогда реактивная сила будет некоторой функцией $f(\eta, \dot{\eta})$. На практике часто используют графическую зависимость $f$ от $\eta$. Данная зависимость для пассивных амортизаторов чаще всего имеет форму кривой гистерезиса, но для активного демпфера класс возможных кривых расширяется.

Задача определения закона демпфирования относится к обратным задачам механики и решается втри этапа. На первом задается возмущенное движение пролетной балки. На втором, экспериментально (численно или на стенде) находиться оптимальный закон реакции демпфера на заданное возмущение. На третьем этапе выбирается конструкция пассивного демпфера, в которую закладывается найденная оптимальная реактивная зависимость. Здесь можно видеть, что конкретная техническая реализация активного демпфера не имеет значения, поскольку вне зависимости от конструкции, это устройство характеризуется 
только реактивной функцией (гистерезисом) и используется только на промежуточной стадии.

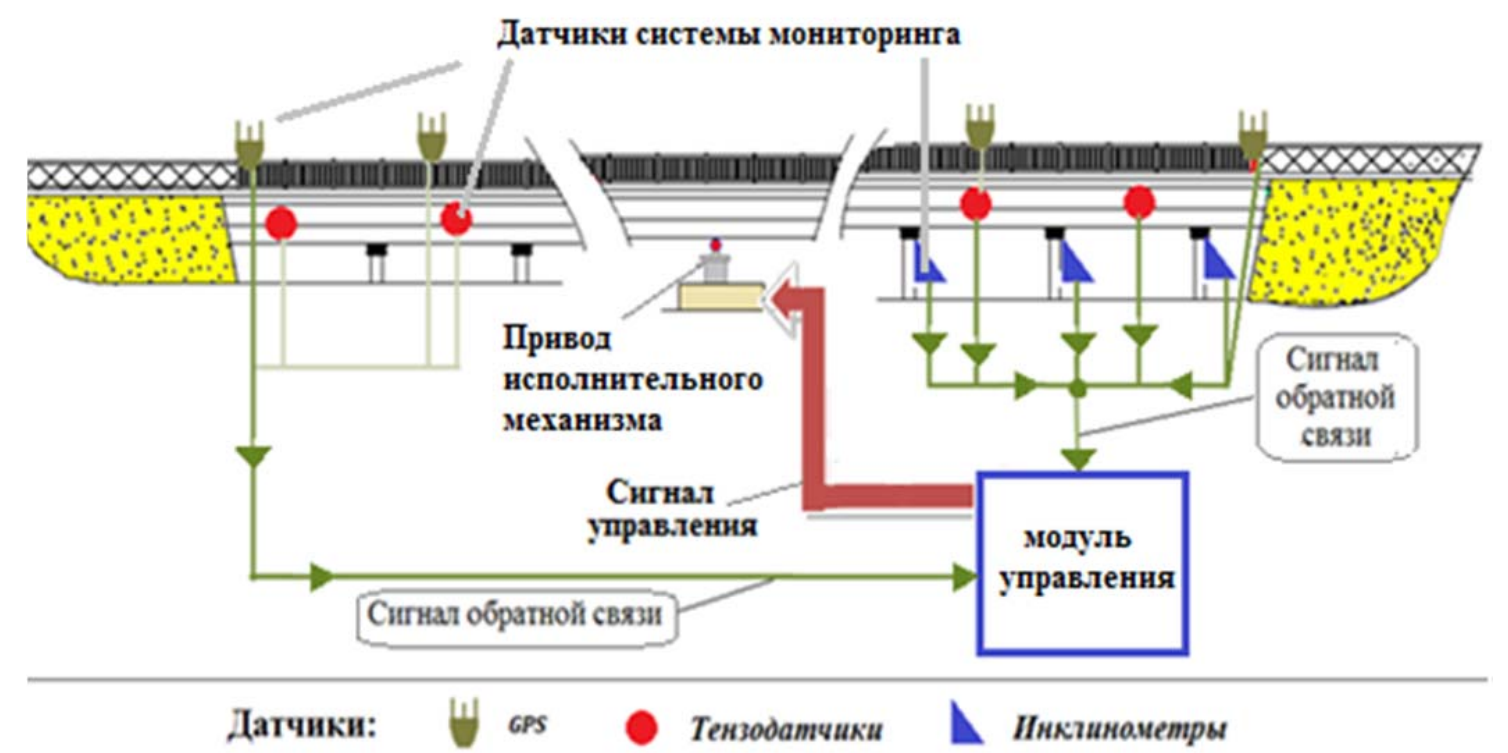

Рис. 1. Активное управление колебаниями пролетной части

Методология. Колебания пролетной части в математических моделях рассматриваются как колебания упругой балки. Классическоеобщее описаниепроцесса представляется рядом гармонических решений многомерного уравнения $[2,3,4]$. С точки зрения инженерных приложений недостатком классических точных решений является их сильная (в смысле равномерной сходимости) зависимость от начальной функции возмущенного профиля прогиба балки в момент времени $t=0$. Каждое точное решение определяется рядом гармонических функций с коэффициентами, определяемыми функцией начального возмущения профиля. Отсюда видно, что опасным колебаниям конструкции, определенным по факту превышения максимальной безопасной для данной конструкции амплитуды, будет соответствовать бесконечное число возмущенных начальных функций. Соответственно каждому возмущению, всего должно быть определено бесконечное число функций $f(\eta, \dot{\eta})$, парирующих эти возмущения, что нереализуемо на практике.

Вместо этого, технически доступно использовать одну или ограниченный набор $f(\eta, \dot{\eta})$, в которых можно варьировать параметры. В таких подходах используются различные приближения, которые основаны на потере части физического содержания. Например, модель TMD[5,6,7] предполагает пролетные части моста твердыми телами, пренебрегая упругими степенями свободы пролетной балки.

Другой недостаток классических точных методов связан с представлением динамических переменных в виде гармонических функций, чем они в реальных случаях, вообще говоря, не являются. Спектр осциллограммы землетрясения, взятый за период $\Delta t$ секунд не коррелирует со спектром того же возмущения в последующем интервале $\Delta t$. Для таких сигналов не существует понятия частоты в исходном физическом смысле, тогда традиционное описание колебаний в базисе функций Крылова не вполнеприменимо. Кроме того, сейсмические воздействия имеют выраженный импульсный характер, описываемый не дифференцируемыми функциями, что ограничивает применимость дифференциальных уравнений. По-видимому, следует явно учитывать то, что колебания конструкции под сейсмическим воздействием представляют собой суперпозицию собственных гармонических тонов и внешних импульсных воздействий. В этом случае имеет смысл рассмотреть некоторый смешанный формализм. 
В новом представлении должно учитываться то, что профили скоростей, прогибов и ускорений, распределенные по длине пролета не несут прямой информации о степени угрозы конструкции и целесообразно перейти к другим переменным, непосредственно выражающие уровень опасности динамического режима.

В работах $[8,9,10]$ для описания демпфирования двух пролетной балки было предложено следующее уравнение:

$$
\left.G_{1} \eta \ddot{(} t\right)=f(\eta, \dot{\eta})+S_{12}(t)-V_{12}(t)-G_{2} g,
$$

где: $G_{1}, G_{2}$, - конструктивные параметры пролетов, $g$ - ускорение силы тяжести.

Конструктивные параметры включают все необходимые физические и геометрические характеристики балок. Функции $S_{12}(t)$ и $V_{12}(t)$ описывают внешние силовые воздействия и прогиб балок соответственно. Эти функции получены путем преобразования свертки над исходными динамическими переменными:

$$
R(t)=\int_{0}^{1} p(x) r(x, t) d x,
$$

здесь $r(x, t)$-соответствует либо распределению внешней силы вдоль пролетной балки, либо профилю прогиба балки, $p$-функция свертки [8]:

$$
p(x)=\frac{1}{2}\left\{\frac{\operatorname{sh}(\lambda)[\sin (\lambda x)-\operatorname{sh}(\lambda x)]}{[1-\operatorname{ch}(\lambda)]}+\cos (\lambda x)-\operatorname{ch}(\lambda x)\right\} .
$$

Тогда прогиб деформируемой балки $\varphi_{k}(x, t)($ индекс $k$ относится к номеру пролета в многопролетной системе) будет характеризоваться изображением профиля прогиба:

$$
A_{k}(t)=\int_{0}^{1} p(x) \varphi_{k}(x, t) d x,
$$

а внешнее силовое поле $s_{k}(x, t)$ его изображением:

$$
S_{k}(t)=\int_{0}^{1} p(x) s_{k}(x, t) d x .
$$

Этим способом осуществляется введение слабой меры динамических функций в описание процесса демпфирования колебаний пролетов.Величины (4а) и (4в) входят в уравнение (1) в виде некоторых комбинаций, обозначенных здесь соответственно $V_{12}(t)$ и $S_{12}(t)$. Конкретный вид выражений зависит от числа пролетов и при качественном рассмотрении принципов активного демпфирования может быть опущен.

По ряду причин уравнение (1) в величинах в слабой мере для инженеров полезнее, чем традиционно используемыми уравнениями колебания балки с решением в базисе функций Крылова.Во-первых, данный математический формализм не содержит уравнений в частных производных и позволяет связать демпфер $f(\eta, \dot{\eta})$ с возмущениями пролетной части системой обыкновенных дифференциальных уравненийуправления с обратной связью $[10,11]$.

Во-вторых, использование интегральных динамических величин (4а) и (4в) вместо точечных смещений и скоростей позволяет нивелировать наличие разрывов и сдвигов вдоль пространственной координаты, характерных при ударных воздействиях.

В-третьих, интегральные характеристики деформации и напряжения характеризуют конструкцию в целом и могут служить значимым индикатором наличия аномальных воздействий и движений.

В-третьих (см. ниже), данный подход устраняет свойственную точным решениям избыточность, связанную с непрерывной зависимостью классических решений от начальных условий. Это свойство рассматривается ниже.

Физический и инженерный смысл данного подхода иллюстрирует рис. 2. Здесь в координатах $\boldsymbol{P}$ - импульса привода демпфера и $\eta$ - его отклонения от равновесного положения изображены фазовые траектории процесса демпфирования. 


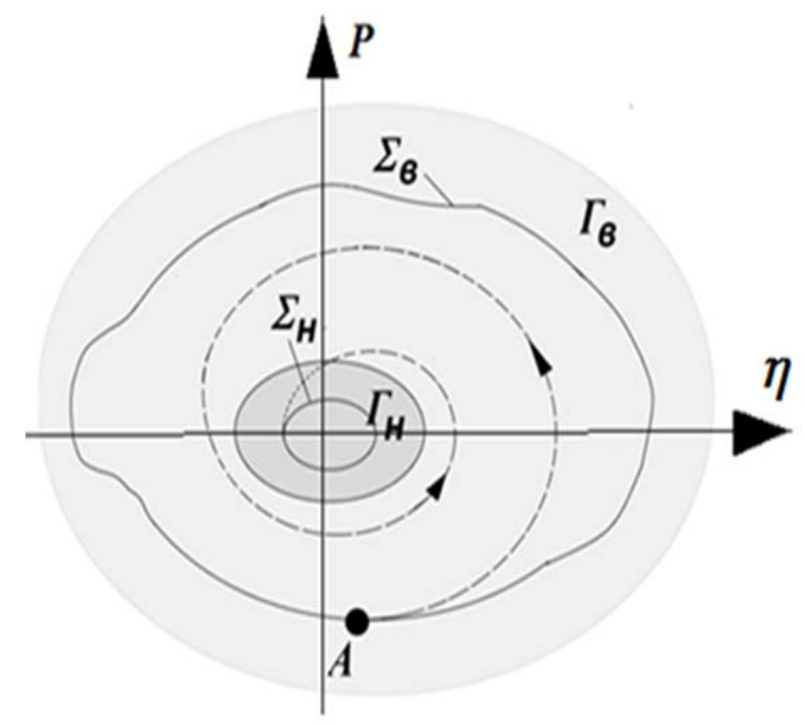

Рис. 2. Фазовые траектории активного демпфера

В традиционном подходе рассматривается переход от конкретного возмущенного движения к нормальному (неопасному) колебанию под действием реактивной силы демпфера. Например, траектория от возмущенного движения $\Sigma_{\text {в }}$ к невозмущенному колебанию $\Sigma_{\mathrm{H}}$. В этом случае функция $\Sigma_{\mathrm{H}}$ полностью определена начальным возмущенным движением $\Sigma_{\text {в }}$.

Такая зависимость от начальных условий аналогична сильной сходимости и, соответственно эти решения можно называть решениями в сильной мере.В слабой мере рассматриваются сразу полные классы возмущенных движений $\Gamma_{\text {в }}$ о отношению к классу нормальных движений $\Gamma_{\text {н }}$. При работе демпфера, для каждой функции из возмущенного класса, любая функция из невозмущенного класса является предельным циклом. Существует множество возмущенных классов, для каждого из которых существует единственная функция вида $f(\eta, \dot{\eta})$,переводящая возмущение в класс нормальных движений.

Напрактике воздействие на режим колебаний со стороны активного демпфера осуществимо через изменение гибкости механического колебательного контура и адекватным выбором конкретного вида реактивной силы - $f(\eta, \dot{\eta})$.

Регулирование гибкости сводится к подключению или отключению дополнительных балластных масс; другой способ - подключение или отключение упругих рессорных подвесов. Управление реактивной силой демпфера состоит в задании закона реакции демпфера $f(\eta, \dot{\eta})$, обеспечивающего требуемый гистерезис демпфирования. В этом случае для создания гистерезиса требуется, чтобы реактивная сила зависела также и от скорости привода $\dot{\eta}$.

В расчетных схемах [9] для эмуляции активного демпфера был использован закон вида:

$$
f(\eta, \dot{\eta})=f_{0}+a \eta^{n}+b \dot{\eta}^{m}
$$

где $f_{0}-$ постоянная сила трения в демпфере,

$a, n, m$ - параметры устройства, которые в активных устройствах можно менять.

Результаты. На рис. 3 показан переход в численном расчете от возмущенного движения двух балочных пролетов (рис. 1) разной длины с демпфером в точке сопряжения балок к нормальному предельному циклу. Возмущение конструкции эмулировалось случайным импульсным сигналом.

Класс возмущенных функций определяется по виду реактивной силы, осуществляющей его редукцию к нормальному предельному циклу. Если две различные 
функции возмущения приводятся к нормальному режиму под воздействием одной реактивной силы, то эти две функции принадлежат к одному классу.

К классам возмущенных функций относятся также и, описанные выше случаи движений пролетных частей с нормальными амплитудами, но содержащие опасные для некоторых элементов конструкции тоны.
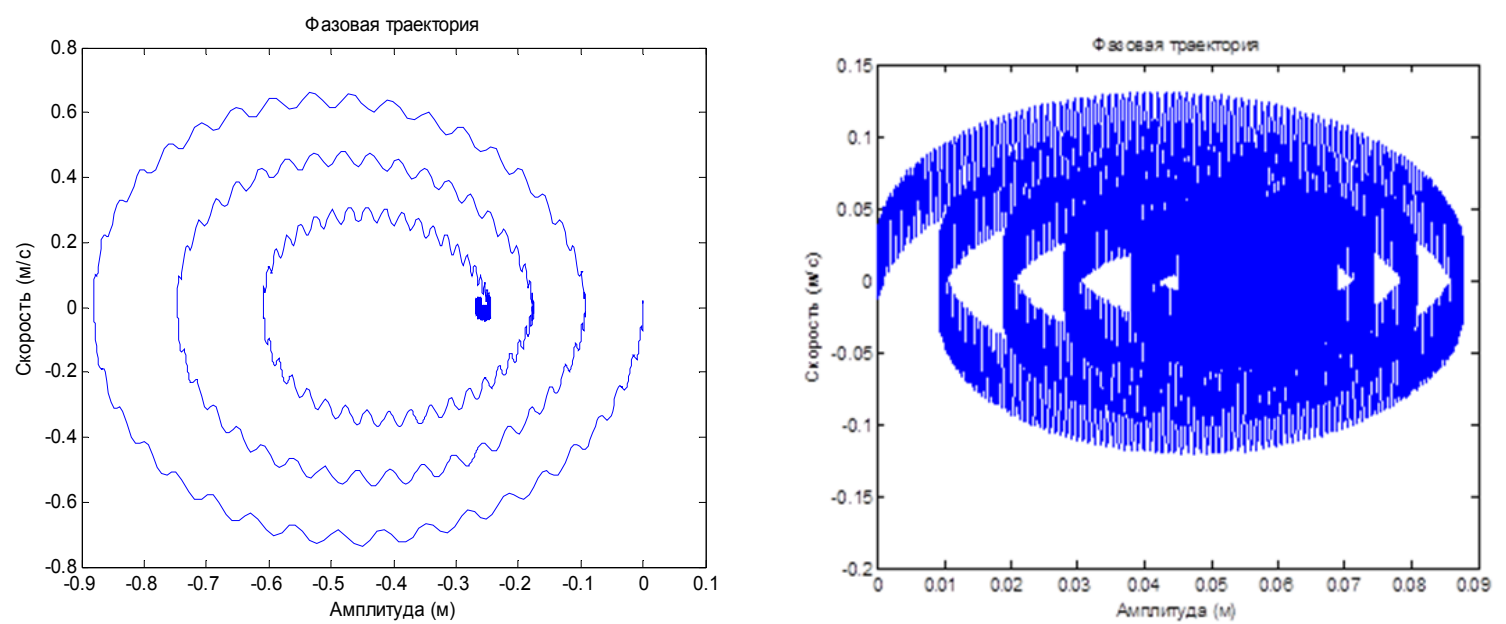

Рис. 3. Фазовая траектория в увеличенном и фактическом масштабах

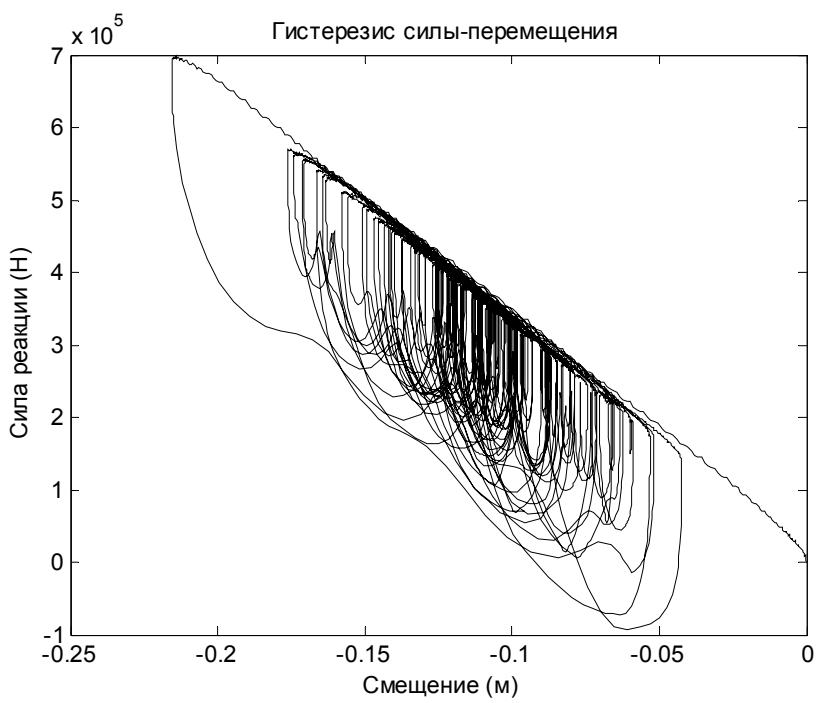

Рис. 4. Гистерезис нагрузки демпфера

При гашении колебаний точка зависимости силы реакции от смещения демпфера описывает замкнутые петли, полная площадь которых равна энергии поглощенной и рассеянной демпфером при амортизации колебаний.

Существование в слабой мере траекторий связывающих предельный цикл (нормальное движение) с классами возмущенных движений говорит о том, что традиционное решение в сильной мере избыточно для инженерных приложений. На практике точное (сильное) решение, во-первых, не всегда можно получить, во-вторых, менее точные решения в слабой мере, позволяют упростить используемые уравнения, сохранив при этом основные характеристики влияния собственных упругих степеней свободы балок на динамику колебаний.

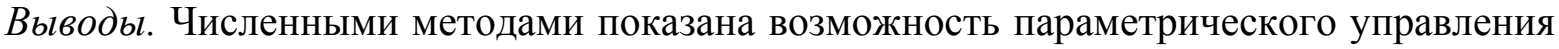
демпфирования вибраций несущей балки пролетной части моста при воздействии нерегулярной ударной нагрузки. 


\section{Список литературы}

1. Эресуннский мост. / Официальный сайт [электронный ресурс]:, режим доступа: свободный . - https://www.oresundsbron.com/en/start

2. Крылов А. Н. О численном решении уравнения, которым в технических вопросах определяются частоты малых колебаний материальных систем [Текст] / А.Н. Крылов // Известия Академии наук ССCP. VII серия. Отделение математических и естественных наук. - 1931. - выпуск 4, с. 491-539.

3. Тимошенко С.П. Колебания в инженерном деле [Текст] / С. Тимошенко - М.: «Наука», 1967. - 44 с.

4. Колебания линейных систем : справочник [Текст] / В.В. Болотин и др. // под ред. B.В. Болотина /// т.1. - Вибрации в технике: Справочник. В 6-ти томах.- М.: Машиностроение, 1978.-352 с.

5. Japan Road Association (JRA), "Specification for highway bridges, part II steel

6. bridge", 2002. (inJapanese)

7. JRA, "Guideline for fatigue design of steel highway bridges", 2002. (in Japanese) Japan Society of Civil Engineering, "Fatigue of orthotropic steel bridge deck",Steel Structures Series No.19, pp.63-75, 2010. (in Japanese).

8. Тулеушова Р.Ж. Описание динамики колебаниями мостовой конструкции в слабой мере [Текст] / Р.Ж.Тулеушова // Актуальные проблемы гуманитарных и естественных наук. - 2016. - №6 (89), Ч1. - с.149.

9. Тулеушова Р.Ж., Наурызбаев М.К. Моделирование параметрического управления вибрациями мостовой балки [Текст] / Р.Ж.Тулеушова // Актуальные проблемы гуманитарных и естественных наук. - 2016. - № 10, Ч1.

10. Тулеушова Р.Ж. Особенности описания колебаний мостовых пролетов при сейсмическом воздействии [Текст] / Р.Ж. Тулеушова, М.К.Наурызбаев // Актуальные проблемы гуманитарных и естественных наук. - 2016. - № 10, Ч1.

11. Dispositividipendentidallavelocita - [Электронный ресурс] / Режим доступа:http://www.fipindustriale.it/public/divisione_industriale/dispositivi_antisismici свободный. - Загл. с экрана.

12. Кутуев М.Д. Метод решения оптимизационной задачи в сейсмозащите сооружений [Текст] / М.Д.Кутуев, М.Ч.Апсеметов, М.С.Дильдаев, Н.У.Шамшиев. // Вестник КГУСТА, - 2017. №2(56). - c.154-163. 